\title{
Erratum to: A new process chain for producing bulk metallic glass replication masters with micro- and nano-scale features
}

\author{
Pierre C. Vella ${ }^{1,3} \cdot$ Stefan S. Dimov ${ }^{1}$ Emmanuel Brousseau ${ }^{2} \cdot$ Ben R. Whiteside ${ }^{4}$. \\ Colin A. Grant ${ }^{5}$. Cristina-Luminita Tuinea-Bobe ${ }^{5}$
}

Published online: 26 January 2016

(C) Springer-Verlag London 2016

Erratum to: Int J Adv Manuf Technol Volume 76, Issue

$$
\text { 1-4, pp 523-543 }
$$

DOI: $10.1007 / s 00170-014-6148-1$

In the version of this article initially published, the names of two authors were omitted. The correct list of authors for the article is: Pierre C. Vella, Stefan S. Dimov, Emmanuel Brousseau, Ben R. Whiteside, Colin A. Grant, CristinaLuminita Tuinea-Bobe. The affiliation of Colin A. Grant and Cristina-Luminita Tuindea-Bobe is the University of Bradford, UK.

The online version of the original article can be found at http://dx.doi.org/ 10.1007/s00170-014-6148-1.

Pierre C. Vella

pvella@eng.um.edu.mt

1 School of Engineering and Informatics, University of Birmingham, Edgbaston, Birmingham B15 2TT, UK

2 Cardiff School of Engineering, Cardiff University, Cardiff CF24 3AA, UK

3 Department of Industrial and Manufacturing Engineering, University of Malta, Msida MSD2080, Malta

4 The Centre for Polymer Micro and Nano Technology, University of Bradford, Bradford, West Yorkshire BD7 1DP, UK

5 University of Bradford, Bradford, UK 